\title{
A decade of hepatitis $C$ at the University of Cape Town/Groote Schuur Hospital Liver Clinic, South Africa, in the pre-direct-acting antivirals era
}

\author{
R Nordien, MB ChB, FCP (SA), MMed (Medicine); M W Sonderup, B Pharm, MB ChB, FCP (SA), MMed (Medicine), FRCP (Lond); \\ C W Spearman, MB ChB, FCP (SA), MMed (Medicine), PhD, FRCP (Lond)
}

Division of Hepatology, Department of Medicine, Faculty of Health Sciences, University of Cape Town and Groote Schuur Hospital, Cape Town, South Africa

Corresponding author: $M$ W Sonderup (msonderup@samedical.co.za)

\begin{abstract}
Background. Hepatitis C virus (HCV) in South Africa (SA) is incompletely characterised and understood. Epidemiological and clinical data will better inform our understanding and assist national policy decision-making. Against the background of more than two decades of clinical challenges in HCV management, the advent of direct-acting antivirals (DAAs) now makes HCV elimination plausible.

Objectives. To better understand the base from which we come, we elected to review and characterise our HCV experience at Groote Schuur Hospital (GSH), Cape Town, SA, in the pegylated interferon (Peg-IFN) and ribavirin (RBV) management era.

Methods. Patients with chronic HCV infection attending the GSH Liver Clinic from 2002 to 2014 were included in the analysis. Relevant data were extracted from a registry and existing clinical records were accessed. Two brands of Peg-IFN were available, and patients treated with the first-generation add-on protease inhibitor telaprevir were included.

Results. A total of 238 patients were included in the analysis (median (interquartile range) 47 (37 - 58) years, 60.5\% males). Males were significantly younger than females ( $43.5(35-52)$ years v. $55(42-64)$ years, respectively) $(p<0.0001)$. The majority were white $(55.9 \%)$ or of mixed ancestry $(21.8 \%), 16.4 \%$ were HIV co-infected, $3.7 \%$ were hepatitis B virus (HBV) co-infected, and 1 patient $(0.4 \%)$ was tripleinfected with HCV, HBV and HIV. The most likely mode of HCV acquisition was blood or blood product exposure prior to 1992 (32.8\%) and injecting drug use (17.6\%), while $30.3 \%$ of patients had no clear risk factor identifiable. Genotypes (GTs) 1 - 5 were observed, with GT-1 (34.9\%) predominating. Of patients who were biopsied $(n=90), 30.0 \%$ had $\geq \mathrm{F} 3$ fibrosis, with $15.6 \%$ cirrhotic. With IL28B polymorphisms, the heterozygous CT (23.9\%) and CC (15.5\%) genotypes were most frequent. Of the patients, $32.6 \%$ accessed Peg-IFN/RBV-based therapy, 6.5\% $(n=5)$ with add-on telaprevir. GT-1 (35.1\%) was most prevalent in the treatment group, followed by GT-3 (26.0\%) and GT-5 (18.2\%); $10.0 \%$ were HIV co-infected. The overall sustained virological response (SVR) rate was $75.3 \%$, with $37.0 \%$ of GT-1 patients not achieving SVR. Of the patients treated, $49.4 \%$ experienced adverse events, including cytopenias (32.5\%) and depression (15.6\%), and $23.4 \%$ required cell support in the form of erythropoietin and/or granulocyte-macrophage colony-stimulating factor.

Conclusions. HCV patients in the Peg-IFN/RBV management era typified the epidemiology of HCV. GT distribution was pangenotypic, and treatment outcomes were encouraging despite treatment challenges. Patient selection, IL28B and sensible support of cytopenias probably accounted for these favourable outcomes. However, numbers treated were limited, and the DAA era of therapy allows for rapid expansion of therapy with now growing numbers of patients and a changing local epidemiology.
\end{abstract}

S Afr Med J 2020;110(2):106-111. https://doi.org/10.7196/SAMJ.2020.v110i2.14208

In 2016, the World Health Assembly of the World Health Organisation approved the first Global Health Sector Strategy to eliminate viral hepatitis. The aim of the strategy is to eliminate viral hepatitis by 2030 , and was defined as a $90 \%$ reduction in the incidence of new infections with a consequent $65 \%$ reduction in mortality from associated liver disease ${ }^{[1]}$ Globally, the prevalence of hepatitis $\mathrm{C}$ virus (HCV) is $1 \%$, equating to an estimated 71.1 million people with active hepatitis $\mathrm{C}$ viraemia and resulting in $\mathrm{HCV}$ being a leading cause of chronic liver disease. The global burden of liver disease continues to increase as a result of hepatitis C-related cirrhosis, hepatocellular carcinoma, liver failure and death. ${ }^{[2]}$ The epidemiology and prevalence of chronic HCV infection in South Africa (SA) remain poorly characterised and understood. Few data exist on defined cohorts of patients with chronic HCV and responses to therapy. The modelled prevalence of HCV viraemia in SA, as of 2015, was $0.4-0.9 \%$, with genotype (GT) $1 \mathrm{~b}(22.1 \%)$ thought to be most frequent, although GTs $1-5$ were prevalent. ${ }^{[2]}$
Following the identification and sequencing of HCV in 1989 by Choo et al., ${ }^{[3]}$ the management of chronic HCV infection has undergone a revolution. Initially, treatment with standard interferon yielded poor response rates. ${ }^{[4]}$ Consequently, pegylated interferon and oral ribavirin (Peg-IFN/RBV) enhanced response, with sustained virological response (SVR) rates of $\sim 50 \% .{ }^{[5]}$ Despite improved SVR rates, treatment was costly and associated with significant adverse effects that resulted in patients discontinuing therapy. Cytopenias associated with drug toxicities sometimes necessitated erythropoietin (EPO) and/or granulocyte-macrophage colony-stimulating factor (GM-CSF) to support treatment sustainability. ${ }^{[5]}$ Factors influencing a positive treatment outcome included the ability to complete $>80 \%$ of the planned duration of treatment with $>80 \%$ of the required doses of Peg-IFN and RBV, ${ }^{[6]}$ the IL28B polymorphism, and the baseline viral load, degree of liver fibrosis and GT. In 2012, the first of a new generation of add-on oral protease inhibitors (PIs), specifically for GT-1 HCV, emerged. These drugs, telaprevir and boceprevir, 
significantly improved SVR rates, but at the expense of enhanced adverse effects. ${ }^{[7-9]}$ The advent of the oral direct-acting antivirals (DAAs) for hepatitis C has revolutionised therapy, with SVR rates now exceeding $95 \%$ with fewer adverse effects. The success of DAA therapy has made HCV elimination now very plausible.

Peg-IFN/RBV initially became available in SA in 2002, and by 2004 the University of Cape Town/Groote Schuur Hospital (UCT/GSH) Liver Clinic was able to access this standard of care for HCV-infected individuals via several mechanisms including compassionate use or expanded access treatment programmes, a hospital-allocated budget to treat a limited number of HCV-infected individuals annually, or private funding.

\section{Objectives}

Given the advent of the DAA era of treatment, we elected to review and describe our experience with interferon-based therapy over a decade-plus period from 2002 to 2014 . We document our local experience with regard to patient demographics, the clinical, biochemical and genetic profile of the study population, viral characteristics, and treatment outcomes (side-effect profile and SVR rates) with interferon-based therapy during this period. No such data exist for SA, and reviewing our experience serves as a benchmark with which to compare the rapidly expanding, albeit currently limited, DAA era of HCV treatment in SA. This study therefore serves to inform national policy decision-making structures of the base from which we have functioned with regard to hepatitis $C$ in SA. Given the need for data in informing such policy, this study aimed to support such policy structures in achieving SA's efforts for viral hepatitis elimination by 2030 .

\section{Methods}

All patients with HCV infection attending the UCT/GSH Liver Clinic from 2002 up to and including 2014 were included. All relevant patient demographic data and clinical characteristics were extracted from a patient registry, in addition to existing clinical records, and recorded in a database. In terms of treatment, two brands of Peg-IFN, viz. Peg-IFN $a-2 b$ (Peg-IntronR; Schering-Plough) and Peg-IFN $a-2 a$ (PegasysR; Hoffman-La Roche) were available in SA during the study period, and patients using either product were included. Standard Peg-IFN/RBV treatment guidelines based on GT were followed. Patients treated with the addition of the first-generation DAA therapy (telaprevir) to their Peg-IFN/RBV regimen were also included in the final analysis.

\section{Laboratory tests}

All baseline biochemical values, a full blood count and the international normalised ratio were recorded. HIV status was confirmed by enzyme-linked immunosorbent assay testing for HIV antibody and p24 antigen, and in patients who were HIV co-infected, the $\mathrm{CD} 4+$ count $($ cells $/ \mu \mathrm{L})$ was recorded at the time of presentation. Viral serological testing (ARCHITECT I or II; Abbott Diagnostics, USA) for hepatitis C (hepatitis C IgG antibody) was positive in all patients, and active viraemia was confirmed by an in-house polymerase chain reaction technique amplifying the 5 NCR region of HCV. Genotype was determined using the Versant HCV Genotype v2.0 Line Probe Assay (Siemens AG, Germany) or through in-house NS5B sequencing. HCV viral loads were measured using the COBAS Ampliprep/Cobas TaqMan v2.0 (Roche Diagnostics, Switzerland). Serological testing for hepatitis A (hepatitis A immunoglobulin G (IgG) antibody) and hepatitis B (hepatitis B surface antigen, HBcore IgG and core immunoglobulin $\mathrm{M}$ antibody) was performed.
Liver biopsy was used to assess fibrosis unless contraindicated (e.g. in haemophiliacs or coagulopathic patients). Liver biopsies were all assessed by one of two experienced liver histopathologists, while clinicopathological assessments were done concurrently with hepatologists. Hepatitis $\mathrm{C}$ was staged and graded using the METAVIR scoring system.

\section{Ethical considerations}

The study was approved by the University of Cape Town Human Research Ethics Committee (ref. no. HREC R045/2014).

\section{Statistical analysis}

Values are expressed as medians and interquartile ranges (IQRs) for continuous variables. Clinical characteristics are summarised using standard descriptive characteristics. Where appropriate, differences between qualitative parameters were explored using the Wilcoxon rank-sum test. Statistical analysis was performed using Excel 2013 (Microsoft, USA).

\section{Results}

A total of 238 patients were evaluated, the majority male (60.5\%, $n=144$ ) (Table 1). The median (IQR) age of the cohort was 47 (37 $58)$ years, but men were significantly younger than women $(43.5$ ( 35 - 52) years v. 55 ( $42-64)$ years, respectively) $(p<0.0001)$. Of note, self-identified heterosexual male patients were significantly older than men who have sex with men (MSM) $(49$ (47 - 51) years v. 40.5 (34 - 45) years, respectively) $(p=0.0002)$. The majority of the patients were white $(55.9 \%)$, followed by mixed ancestry $(21.8 \%)$ and black African (13.9\%). The probable mode of HCV acquisition was predominantly blood or blood product exposure prior to 1992 (32.8\%), parenteral through injecting drug use (IDU) (17.6\%), or parenteral or percutaneous exposure (10.9\%), e.g. needlestick injuries, tattoos, etc. Haemophiliacs comprised $13.4 \%$ of patients. No clear route could be identified in almost a third of patients (30.3\%). In terms of GT distribution (Table 2), GT-1 (34.9\%) predominated, with GT-1a more prevalent than GT-1b $(62.7 \%$ v. $36.3 \%$, respectively). GTs 3,4 and 5 were present in similar frequencies $(18.1 \%, 17.2 \%$, and $16.0 \%$, respectively), with GT-2 least frequent (6.7\%). GT was not identified in $7.1 \%$ of the cohort. The median hepatitis $C$ viral load was $5.6(4.7-6.2) \log _{10} \mathrm{IU} / \mathrm{mL}$. In addition, $16.4 \%$ of the patients were HIV co-infected, with a median baseline CD4+ count of 395 cells $/ \mu \mathrm{L}, 3.7 \%(n=8)$ were hepatitis B co-infected, and 1 patient $(0.4 \%)$ was triple-infected with HIV, HBV and HCV. Of patients screened for hepatitis A immunity (anti-HAV $\mathrm{IgG}), 71.5 \%$ were positive.

Baseline laboratory characteristics, shown in Table 3, demonstrate that median baseline alanine transaminase (ALT) and aspartate transaminase were elevated; however, $29.8 \%$ of patients $(n=71)$ had an ALT level within the laboratory 'normal' range. Liver biopsy results are listed in Table $4(n=90)$. In terms of the METAVIR score, $30.0 \%$ of patients had $\geq \mathrm{F} 3$ fibrosis, with $15.6 \%$ cirrhotic. Most had F2 fibrosis. Ancillary biopsy data demonstrated a high frequency of steatosis (63.3\%), and iron overload was present in $12.2 \%$.

Table 5 notes all ancillary clinical or laboratory data. From 2011, all patients were screened for the $I L 28 B$ allele. The heterozygous IL28B CT allele was most frequent, followed by the homozygous CC or TT alleles. Homozygosity or heterozygosity for the HFE C282Y or $H 63 D$ alleles are highlighted, with homozygosity infrequently observed. Diabetes mellitus was highly prevalent (17.6\%). Although alcohol consumption was not accurately assessed, $16.4 \%$ of patients confirmed regular consumption. 
Table 1. Demographic characteristics of the study population $(N=238)$

\begin{tabular}{|c|c|c|}
\hline Parameter & & $p$-value \\
\hline Male, $n(\%)$ & $144(60.5)$ & \\
\hline Heterosexual, ${ }^{\star} n(\%)$ & $112(47.1)$ & \\
\hline $\mathrm{MSM},{ }^{*} n(\%)$ & $32(13.4)$ & \\
\hline \multicolumn{3}{|l|}{ Age $^{\dagger}$ distribution, median (IQR) } \\
\hline Total cohort & $47(37-58)$ & \\
\hline Male/female & $43.5(35-52) / 55(42-64)$ & 0.0001 \\
\hline Heterosexual/MSM & $49(47-51) / 40.5(34-45)$ & 0.0002 \\
\hline \multicolumn{3}{|l|}{ Ethnicity, ${ }^{\ddagger} n(\%)$} \\
\hline Asian & $20(8.4)$ & \\
\hline Black & $33(13.9)$ & \\
\hline Mixed ancestry & $52(21.8)$ & \\
\hline White & $133(55.9)$ & \\
\hline \multicolumn{3}{|l|}{ Mode of acquisition of HCV, $n(\%)$} \\
\hline Transfusions ${ }^{\varsigma}$ & $78(32.8)$ & \\
\hline Unknown & $72(30.3)$ & \\
\hline IDU & $42(17.6)$ & \\
\hline Parenteral/percutaneous & $26(10.9)$ & \\
\hline Unsafe medical procedures & $13(5.5)$ & \\
\hline Sexual encounter & $5(2.1)$ & \\
\hline Perinatal, mother to child & $2(0.8)$ & \\
\hline Haemophiliac, $n(\%)$ & $32(13.4)$ & \\
\hline \multicolumn{3}{|c|}{$\begin{array}{l}\text { MSM = men who have sex with men; IQR = interquartile range; } \mathrm{HCV}=\text { hepatitis } \mathrm{C} \text { virus; } \mathrm{IDU}=\text { injecting drug use. } \\
\text { *Sexual orientation was self-reported. } \\
\text { tage (years at pt presentation. } \\
\text { tethinicity was self-reported. } \\
\text { 'Slood and blood products, including haemophiliacs. } \\
\text { 'Surgical/dental/orthodontic procedures. }\end{array}$} \\
\hline
\end{tabular}

Only 32.3\% ( $n=77)$ of HCV-infected patients accessed Peg-IFN/ RBV-based therapy (Table 6). Five patients received add-on firstgeneration PI treatment, viz. telaprevir. These 5 patients were all GT-1, and 2 of them had previously failed treatment. GT distribution in the treatment group was as follows: GT-1 35.1\%, GT-2 11.7\%, GT-3 26.0\%, GT-4 9.1\% and GT-5 18.2\%. Eight treated patients (10.4\%) were HIV co-infected, and 1 was triple-infected. Most patients (71.5\%) treated had $\geq \mathrm{F} 2$ fibrosis (Table 7), with $28.6 \% \geq \mathrm{F} 3$ and $14.3 \%$ compensated cirrhotics. The overall SVR was $75.3 \%$, with more than half of the patients (55.8\%) achieving rapid virological response (RVR) and $84.4 \%$ achieving early virological response (EVR). Of the 19 patients not achieving SVR, the majority (52.6\%) were GT-1. All GT-2 patients achieved SVR. Of patients tested for IL28B prior to treatment, $77.4 \%, 66.1 \%$ and $40.3 \%$ of the CC, CT and TT GTs, respectively, achieved SVR. The median (IQR) HCV viral load (log copies $/ \mathrm{mL}$ ) did not differ between those who did and did not achieve $\operatorname{SVR}(5.85$ (5.0 - 6.4) and 5.8 (5.45 - 6.45), respectively) ( $p=0.56)$.

Table 8 demonstrates the event rate of adverse effects related to Peg-IFN/RBV therapy, with $49.4 \%$ of patients experiencing adverse effects. Surprisingly, only a single patient discontinued therapy because of adverse effects. The need for cytopenia support was substantial, with $7.8 \%$ and $7.8 \%$ of patients, respectively, requiring EPO for anaemia to maintain the RBV dose or GM-CSF support to maintain the Peg-IFN dose for treatment-related neutropenia. An equal number of patients required a combination of EPO and GM-CSF (7.8\%). Psychiatric side-effects, especially depression, affected $15.6 \%$ of patients.

\section{Discussion}

There are several observations consistent with typical patterns of HCV epidemiology in our Liver Clinic cohort during the period
2002 - 2014. Data now support the existence of two distinct epidemiological patterns of infection that create a bimodal age distribution for chronic hepatitis C. ${ }^{[10]}$ The first group are older and probably acquired infection through a variety of mechanisms including blood or blood product exposure pre-1992, IDU and other parenteral modes of infection. This pattern is clearly reflected in our cohort, with one-third having had blood or blood product exposure prior to 1992. Less represented are recent or current IDUs, who are less likely to present or be referred for therapy given the rigours of PegIFN/RBV-based therapy. Current transmission, in younger patients, is driven predominantly by IDUs and MSM, especially if HIVinfected ${ }^{[11]}$ Consistent with known global HCV epidemiology, in our study men were younger than women, and MSM were significantly younger than non-MSM. In addition, we have previously documented high rates of HCV infection in HIV-positive MSM in Cape Town. ${ }^{[12-14]}$

Globally GTs 1 and 3 predominate, being responsible for $44 \%$ and $25 \%$, respectively, of global HCV infection. ${ }^{[2]}$ In a recent SA study of HCV characteristics in blood donors and the general population for the period 2008 - 2011, GT-1 was observed in 34\%, with GT-5a being most prevalent (36\%). GT-5a accounted for $54 \%$ of infections in black South Africans, with GT-1 seen in $43 \%$ of white South Africans. GTs 3 and 4 occurred at the same frequency (14\%), and least frequent was GT-2. ${ }^{[11-16]}$ The GT distribution in our patient cohort was fairly similar, except for GT-5a. This finding is not unexpected given the generally higher prevalence of GT-5a in the northern half of SA. GT-1 is invariably more prevalent in the southern portion of the country. Similarly, GT- 4 was more prevalent compared with HCV GT distribution studies of the 1990s. ${ }^{[17]}$ This probably reflects patterns of immigration into SA of people from GT-4-predominant parts of Africa over the past 2 - 3 decades. The GT-4 subtype variation also supports this notion. Furthermore, our 


\begin{tabular}{|c|c|}
\hline $\begin{array}{l}\text { HCV viral load }\left(\log _{10} \mathrm{IU} / \mathrm{mL}\right) \text {, median (IQR) } \\
(N=238)\end{array}$ & $5.6(4.7-6.2)$ \\
\hline \multicolumn{2}{|l|}{$\mathrm{GT}, n(\%)(N=238)$} \\
\hline GT-1 & $83(34.9)$ \\
\hline GT-2 & $16(6.7)$ \\
\hline GT-3 & $43(18.1)$ \\
\hline GT-4 & $41(17.2)$ \\
\hline GT-5 & $38(16.0)$ \\
\hline Not tested & $17(7.1)$ \\
\hline \multicolumn{2}{|l|}{ GT subtype, $n(\%)^{*}$} \\
\hline GT-1a & $42(17.6,62.7)$ \\
\hline GT-1b & $25(10.5,37.3)$ \\
\hline GT-2a & $4(1.7,50.0)$ \\
\hline GT-2b & $4(1.7,50.0)$ \\
\hline GT-3a & $36(15.1,97.3)$ \\
\hline GT-3b & $1(0.4,2.7)$ \\
\hline GT-4a & $2(0.8,22.2)$ \\
\hline GT-4c & $2(0.8,22.2)$ \\
\hline GT- $4 \mathrm{e}$ & $5(2.1,55.6)$ \\
\hline GT-5a & $30(12.6,100)$ \\
\hline Not tested & $17(7.1)$ \\
\hline \multicolumn{2}{|l|}{ Serological markers } \\
\hline $\mathrm{HAV}^{\dagger} n(\%)(N=123)$ & $88(71.5)$ \\
\hline $\mathrm{HBV},{ }^{\ddagger} n(\%)(N=219)$ & $8(3.7)$ \\
\hline HIV, $n(\%)(N=189)$ & $31(16.4)$ \\
\hline $\begin{array}{l}\text { Baseline CD4+ count (cells } / \mu \mathrm{L}) \text {, median } \\
\text { (IQR) }\end{array}$ & $395(272-650)$ \\
\hline $\mathrm{HIV} / \mathrm{HBV} / \mathrm{HCV}^{\varsigma}$ & $1(0.4)$ \\
\hline \multicolumn{2}{|c|}{ 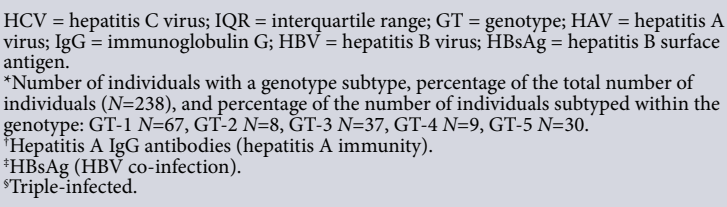 } \\
\hline
\end{tabular}

Table 3. Baseline laboratory characteristics of the study population $(N=238)$

\begin{tabular}{lll}
\hline Parameter & $\begin{array}{l}\text { Laboratory } \\
\text { reference range }\end{array}$ & Median $(\mathrm{IQR})$ \\
\hline Total bilirubin $(\mu \mathrm{mol} / \mathrm{L})$ & $0-21$ & $10(7-16)$ \\
Albumin $(\mathrm{g} / \mathrm{L})$ & $35-52$ & $43(38-47)$ \\
ALT $(\mathrm{U} / \mathrm{L})$ & $5-40$ & $60(35-109)$ \\
AST $(\mathrm{U} / \mathrm{L})$ & $5-40$ & $50(32-89)$ \\
$\mathrm{INR}$ & $0.9-1.2$ & $1(0.9-1.1)$ \\
Haemoglobin $(\mathrm{g} / \mathrm{dL})$ & $13.0-17.0$ & $14.4(13.1-15.8)$ \\
White cell count $\left(\times 10^{9} / \mathrm{L}\right)$ & $4.0-10.0$ & $6.2(5-7.8)$ \\
Platelets $\left(\times 10^{9} / \mathrm{L}\right)$ & $137-373$ & $225(156-278)$ \\
Alpha-fetoprotein $(\mu \mathrm{g} / \mathrm{L})$ & $0.0-7.0$ & $3.9(2.4-6.8)$ \\
Ferritin $(\mu \mathrm{g} / \mathrm{L})$ & $30-400$ & $189(90-438)$ \\
IQR $=$ interquartile range; ALT $=$ alanine aminotransferase; AST $=$ aspartate \\
aminotransferase; INR = international normalised ratio.
\end{tabular}

study again reinforces the HCV pangenotypic status (GTs 1 - 5) of $\mathrm{SA}$, which has implications for elimination programmes based on DAA therapy in the future.

In terms of mode of HCV acquisition, IDU and blood or blood product exposure dominated. This finding is unsurprising, but in a

\section{Table 4. Liver biopsy results $(N=238)$}

\begin{tabular}{ll}
\hline & $\boldsymbol{n}(\%)$ \\
\hline Biopsies performed & $90(37.8)$ \\
Presence of steatosis $(N=90)$ & $57(63.3)$ \\
Presence of iron $(N=90)$ & $11(12.2)$ \\
METAVIR activity score ${ }^{*}(N=90)$ & \\
0 & $3(3)$ \\
1 & $48(53)$ \\
2 & $25(28)$ \\
3 & $14(16)$ \\
4 & 0 \\
METAVIR fibrosis score ${ }^{\dagger}(N=90)$ & \\
0 & $9(10)$ \\
1 & $15(16.7)$ \\
2 & $39(43.3)$ \\
3 & $13(14.4)$ \\
4 & $14(15.6)$ \\
$* 0=$ no active inflammation; $1=$ minimal inflammation; 2 = moderate inflammation; \\
$3=$ severe $4=$ very severe. \\
${ }^{+0}=$ no fibrosis; $1=$ minimal fibrosis; $2=$ scarring fibrosis; $3=$ bridging fibrosis; \\
$4=$ cirrhosis.
\end{tabular}

Table 5. Ancillary clinical and laboratory data $(N=\mathbf{2 3 8})$

\begin{tabular}{ll}
\hline Diabetes mellitus, $n(\%)$ & $42(17.6)$ \\
HbA1c (\%), median (IQR) & $7.7(6.8-8.8)$ \\
Hereditary haemochromatosis (HFE genes), $n(\%)$ & \\
C282Y heterozygous & $5(2.1)$ \\
C282Y homozygous & $1(0.4)$ \\
H63D heterozygous & $19(8.0)$ \\
H63D homozygous & $1(0.4)$ \\
Not tested & $147(61.8)$ \\
Alcohol consumption, ${ }^{*} n(\%)$ & \\
Yes & $39(16.4)$ \\
No & $199(83.6)$ \\
IL28B allele, $n(\%)$ & \\
CC & $37(15.5)$ \\
CT & $57(23.9)$ \\
TT & $18(7.6)$ \\
Not tested & $126(52.9)$ \\
${ }^{*}$ Self-reported. &
\end{tabular}

considerable proportion of patients, no clear mode was identifiable. Factors such as traditional or unsafe medical practices may account for these patients' hepatitis C. Not identifying a mode of transmission creates substantial difficulty when making recommendations on population screening for hepatitis $\mathrm{C}$ in SA as part of a national elimination strategy.

The median ALT, as anticipated, was elevated; however, the cohort demonstrates the phenomenon of a laboratory 'normal' ALT value in a substantial component (29.8\%) of patients, a finding that is well recognised in patients with chronic hepatitis $\mathrm{C}$, where typically a quarter can have so-called normal transaminases. ${ }^{[18]}$ It highlights the point that ALT is a poor surrogate marker of chronic hepatitis $\mathrm{C}$ infection. Testing for hepatitis $\mathrm{C}$ antibody remains the screening test of choice and HCV RNA determination, the marker of viraemia.

During the time period under review, only a third of patients accessed Peg-IFN/RBV-based therapy. This finding is not unexpected for several reasons, including the limited funding available to treat patients, the significant cost of Peg-IFN/RBV treatment, the adverse effects of treatment and contraindications to treatment. In 
Table 6. PEG-IFN/RBV-treated patients: SVR according to GT distribution

\begin{tabular}{lllll}
\hline & \multicolumn{4}{c}{ GT distribution } \\
\cline { 2 - 5 } & GT-1 & GT-2 & GT-3 & GT-4 \\
\hline Total treated $(N=77), n(\%)$ & $27(35.1)$ & $9(11.7)$ & $20(26.0)$ & $7(9.1)$ \\
SVR, $n(\%)$ & $17 / 27(63)$ & $9 / 9(100)$ & $18 / 20(90.0)$ & $4 / 7(57.0)$ \\
No SVR, $n(\%)$ & $10 / 27(37)$ & 0 & $2 / 20(10.0)$ & GT-5 \\
PEG-IFN/RBV = pegylated interferon and ribavirin; SVR = sustained virological response, defined as undetectable HCV-RNA 24 weeks after the end of treatment; GT = genotype; \\
HCV = hepatitis C virus.
\end{tabular}

Table 7. PEG-IFN/RBV-treated patients: liver biopsy results, virological response and treatment duration

\begin{tabular}{|c|c|}
\hline & $n(\%)$ \\
\hline \multicolumn{2}{|c|}{ Liver biopsy results $(N=49)$} \\
\hline \multicolumn{2}{|c|}{ METAVIR activity score ${ }^{\star}$} \\
\hline 0 & $1(2.0)$ \\
\hline 1 & $31(63.3)$ \\
\hline 2 & $11(22.5)$ \\
\hline 3 & $6(12.2)$ \\
\hline 4 & 0 \\
\hline \multicolumn{2}{|c|}{ METAVIR fibrosis score ${ }^{\dagger}$} \\
\hline 0 & $5(10.2)$ \\
\hline 1 & $9(18.4)$ \\
\hline 2 & $21(42.9)$ \\
\hline 3 & $7(14.3)$ \\
\hline 4 & $7(14.3)$ \\
\hline \multicolumn{2}{|c|}{ Virological response $(N=77)$} \\
\hline SVR & $58(75.3)$ \\
\hline RVR & $43(55.8)$ \\
\hline EVR & $65(84.4)$ \\
\hline \multicolumn{2}{|c|}{ Treatment duration (weeks) $(N=77)$} \\
\hline 24 & $38(49.4)$ \\
\hline 48 & $37(48.1)$ \\
\hline 72 & $4(5.2)$ \\
\hline \multicolumn{2}{|c|}{ 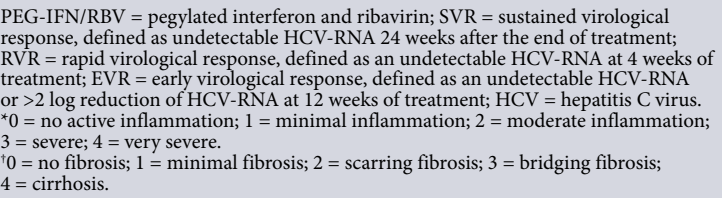 } \\
\hline
\end{tabular}

addition, patients with difficult-to-treat HCV genotypes or HIV co-infection with minimal fibrosis were 'warehoused' in anticipation of more effective therapies with fewer side-effects. The number of patients treated was substantial, however, and represents the single largest reported cohort of patients treated with Peg-IFN/RBV-based hepatitis $\mathrm{C}$ therapy in SA to date. Given that almost two-thirds of patients treated were the more difficult GTs 1,4 or 5 (35.1\% GT-1 alone), almost one-third had advanced fibrosis and $10 \%$ were HIV co-infected, treatment outcomes in terms of SVR in $75.3 \%$ of patients were very good. Given that SVR rates in most large cohort studies ranged between $54 \%$ and $66 \%$, our outcomes were particularly encouraging and several reasons probably accounted for this. Firstly, patient selection is important in terms of those more motivated for treatment and with more favourable IL28B genotypes, while the judicious use of supportive therapy enables maximal doses of PegIFN and RBV to be used. In terms of patient selection, those with liver biopsies demonstrating more necro-inflammatory activity and greater degrees of fibrosis were more likely to be offered therapy.

Looking at the IL28B single-nucleotide polymorphism, of patients tested, most had the more favourable IL28B CC or CT genotype as

\begin{tabular}{ll} 
Table 8. Treatment adverse effects $(\boldsymbol{N}=\mathbf{7 7})$ & \\
\hline \multicolumn{2}{l}{$\boldsymbol{n}(\%)$} \\
\hline Patients who experienced adverse effects & $38(49.4)$ \\
Patients who stopped therapy because of adverse effects & $1(1.3)$ \\
Side-effects experienced & \\
Neutropenia & $10(11.7)$ \\
Anaemia & $4(5.2)$ \\
Thrombocytopenia & $4(5.2)$ \\
Bicytopenia & $3(3.9)$ \\
Pancytopenia & $4(5.2)$ \\
Psychiatric & $7(9.1)$ \\
Psychiatric and cytopenia & $5(6.5)$ \\
Rash & $1(2.6)$ \\
Cell support required & \\
EPO & $6(7.8)$ \\
GM-CSF & $6(7.8)$ \\
EPO + GM-CSF & $6(7.8)$ \\
EPO = erythropoietin; GM-CSF = granulocyte-macrophage colony-stimulating factor.
\end{tabular}

opposed to the less favourable TT genotype. Data from the large IDEAL study were the first to demonstrate the significant predictive value of the relevant $I L 28 B$ genotype in increasing the odds ratio in favour of SVR. The IL28B CC genotype resulted in an odds ratio that increased the likelihood of SVR 3 - 7 times. ${ }^{[19]}$ In keeping with this finding, in our study $77 \%$ and $66 \%$, respectively, of the CC and CT GT patients achieved SVR, as opposed to $40 \%$ of the TT GT patients. Treatment outcomes are influenced by on-treatment factors such as achieving RVR and the ability to maintain maximum doses of Peg-IFN and RBV. Given the cytopenic side-effects of Peg-IFN/RBV, the use of GM-CSF to maintain absolute neutrophil counts and EPO to maintain haemoglobin levels is crucial to allow for continued regular administration of Peg-IFN/RBV at recommended doses. ${ }^{[5]}$ Of our treated patients, almost a quarter $(23.4 \%)$ received GM-CSF and/or EPO support to allow for continued dosing of Peg-IFN/RBV, respectively. This support enabled patients to complete the required duration of therapy while tolerating maximal doses and probably contributed to the SVR rates achieved in our cohort. Maintaining Peg-IFN and RBV dosing at $\geq 80 \%$ has a positive effect on SVR likelihood. ${ }^{[6]}$

Adverse events, as anticipated, were frequent. Rates of psychiatric adverse events, typically depression, have been reported to occur in 5 - $20 \%$ of patients. ${ }^{[20,21]}$ Just over $15 \%$ of our patients were diagnosed with depression that required intervention with an antidepressant and/or counselling and support. The rates of adverse events in our treated patient cohort support the difficulties of Peg-IFN/RBV-based therapy. Adverse effects tend to occur within first 12 weeks, so while duration is affected, need for support was no different between the two groups, viz. 24/48 weeks. We were fortunate in that only 1 patient discontinued therapy because of adverse events. Adverse effects were 
compounded in patients using the add-on PI therapy, telaprevir. While numbers were small, $80 \%$ of GT-1 patients using telaprevir in conjunction with Peg-IFN/RBV achieved SVR.

\section{Study limitations}

With regard to study limitations, this was a retrospective study and not all required data were available. IL28B genotyping only became available in 2011. Resource constraints resulted in a limited number of patients being treated, and very careful selection was required to ensure that those treated had the greatest likelihood of cure. This selection bias may have inflated SVR rates. There may be underrepresentation of certain high-risk populations such as IDUs, because they are less likely to present or be referred.

\section{Conclusions}

The HCV patient population in the Peg-IFN/RBV era in our clinic represented the more typical epidemiology of $\mathrm{HCV}$ acquisition, either via previous IDU or blood transfusion prior to 1992. Notably, our patient population is pangenotypic in GT distribution, and our treatment outcomes during this era were commendable despite significant treatment challenges and adverse events. Careful patient selection, favourable IL28B alleles and sensible cytopenia support as well as on-treatment responses with high rates of RVR and EVR probably account for these good results. Our study is the first to document outcomes of interferon-based therapy for hepatitis $\mathrm{C}$ in SA. It will serve as a benchmark for comparison with the performance of DAAs in SA. Given the need for data in informing national policy decision-making structures and the fact that no such data exist, this study serves to inform and support such policy structures, and encourage government to provide the economic infrastructure required to support SA's effort for viral hepatitis elimination by 2030 , in which DAA therapy for hepatitis $\mathrm{C}$ will be the foundation of management.

\section{Declaration. None.}

Acknowledgements. RN wishes to acknowledge CWS and MWS for their support, expertise and contributions in the development of this manuscript, as well as their involvement in the ongoing care of these patients.

Author contributions. RN conducted the study and drafted the manuscript. MWS and CWS contributed equally to the study and manuscript development.
Funding. None.

Conflicts of interest. None.

1. World Health Organization. Meeting of the International Task Force for Disease Eradication, June 2017. Wkly Epidemiol Rec 2017;92(37):537-556

2. Blach S, Zeuzem S, Manns M, et al. Global prevalence and genotype distribution of hepatitis $C$ virus infection in 2015: A modelling study. Lancet Gastroenterol Hepatol 2017;2(3):161-176. https://doi. org/10.1016/s2468-1253(16)30181-9

3. Choo QL, Weiner AJ, Overby LR, Bradley DW, Houghton M. Isolation of cDNA clone derived from a blood-borne non-A, non-B viral hepatitis genome. Science 1989;244(4902):359-362. https://doi. a blood-borne non- $A$, non- $B$
org $/ 10.1126 /$ science. 2523562

4. Di Bisceglie AM, Martin P, Kassianides C, et al. A randomized, double-blind, placebo-controlled trial of recombinant human alpha-interferon therapy for chronic non-A, non-B (type $C$ ) hepatitis. J Hepatol 1990;11(Suppl 1):S36-S42. https://doi.org/10.1016/0168-8278(90)90161-j

5. McHutchison JG, Lawitz EJ, Shiffman ML, et al. Peginterferon alfa-2b or alfa-2a with ribavirin for treatment of hepatitis C infection. N Engl J Med 2009;361(6):580-593. https://doi.org/10.1056/ NEJMoa0808010

6. McHutchison JG, Manns M, Patel K, et al. Adherence to combination therapy enhances sustained response in genotype-1-infected patients with chronic hepatitis C. Gastroenterology 2002;123(4):1061response in genotype-1-infected patients with

7. McHutchison JG, Manns MP, Muir AJ, et al. Telaprevir for previously treated chronic HCV infection. 7. McHutchison JG, Manns MP, Muir AJ, et al. Telaprevir for previously treated chro
N Engl J Med 2010;362(14):1292-1303. https://doi.org/10.1056/NEJMoa0908014

8. Bacon BR, Gordon SC, Lawitz E, et al. Boceprevir for previously treated chronic HCV genotype 1 infection. N Engl J Med 2011;364(13):1207-1217. https://doi.org/10.1056/NEJMoa1009482

9. Jacobson IM, McHutchison JG, Dusheiko G, et al. Telaprevir for previously untreated chronic hepatitis C virus infection. N Engl J Med 2011;364(25):2405-2416. https://doi.org/10.1056/NEJMoa1012912

10. Centers for Disease Control and Prevention. Hepatitis $C$ virus infection among adolescents and young adults: Massachusetts, 2002 - 2009. MMWR Morbid Mortality Wkly Rep 2011;60(17):537-541.

11. Bruggmann P, Berg T, Ovrehus AL, et al. Historical epidemiology of hepatitis C virus (HCV) in Bruggmann P, Berg T, Ovrehus AL, et al. Historical epidemiology of hepatitis C virus
selected countries. J Viral Hepat 2014;21(Suppl 1):5-33. https://doi.org/10.1111/jvh.12247

12. Tohme RA, Holmberg SD. Is sexual contact a major mode of hepatitis $\mathrm{C}$ virus transmission? Hepatology 2010;52(4):1497-1505. https://doi.org/10.1002/hep.23808

13. Semugoma NP, Rebe K, Sonderup MW, et al. Hepatitis C: A South African literature review and results from a burden of disease study among a cohort of drug-using men who have sex with men in Cape Town, South Africa. S Afr Med J 2017;107(12):1116-1120. https://doi.org/10.7196/SAMJ.2017, v107i12.12623

14. Gogela NA, Sonderup MW, Rebe K, Chivese T, Spearman CW. Hepatitis C prevalence in HIV-infected heterosexual men and men who have sex with men. S Afr Med J 2018;108(7):568-572. https://doi. org/10.7196/SAMJ.2018.v108i7.13041

15. Prabdial-Sing N, Chirwa T, Thaver J, et al. Hepatitis $\mathrm{C}$ genotype distribution in patient and blood donor samples in South Africa for the period 2008 - 2012. J Viral Hepat 2016;23(11):881-888. https:// doi.org/10.1111/jvh.12571

16. Sonderup MW, Afihene M, Ally R, et al. Hepatitis C in sub-Saharan Africa: The current status and recommendations for achieving elimination by 2030. Lancet Gastroenterol Hepatol 2017;2(12):910919. https://doi.org/10.1016/s2468-1253(17)30249-2

17. Smuts H, Kannemeyer J. Genotyping of hepatitis-C virus in South Africa. J Clin Gastroenterol 1995;33(6):1679-1681.

18. Amin J, Kaye M, Skidmore S, Pillay D, Cooper DA, Dore GJ. HIV and hepatitis C coinfection within the CAESAR study. HIV Med 2004;5(3):174-179. https://doi.org/10.1111/j.1468-1293.2004.00207.x

19. Thompson AJ, Muir AJ, Sulkowski MS, et al. Interleukin-28B polymorphism improves viral kinetics and is the strongest pretreatment predictor of sustained virologic response in genotype 1 hepatitis $\mathrm{C}$ virus. Gastroenterology 2010;139(1):120-129.e18. https://doi.org/10.1053/j.gastro.2010.04.013

20. Schaefer M, Capuron L, Friebe A, et al. Hepatitis C infection, antiviral treatment and mental health: A European expert consensus statement. J Hepatol 2012;57(6):1379-1390. https://doi.org/10.1016/j. jhep.2012.07.037

21. Mahajan S, Avasthi A, Grover S, Chawla YK. Incidence of depression in patients with chronic hepatitis C receiving combination therapy of pegylated interferon-alpha and ribavirin. Psychother Psychosom 2014;83(5):308-309. https://doi.org/10.1159/000358527

Accepted 17 July 2019 